\title{
EL CONSULADO BRITÁNICO EN MANILA, EJEMPLO DE SOPORTE INSTITUCIONAL PARA LA PENETRACIÓN EN LOS MERCADOS EXTRAEUROPEOS DEL SIGLO XIX
}

\author{
María Dolores Elizalde \\ Instituto de Historia, CSIC \\ lola.elizalde@cchs.csic.es \\ ORCID 0000-0001-7650-5521
}

Este artículo se centra en el estudio del consulado de Gran Bretaña en Manila, como ejemplo de soporte institucional para la penetración y consolidación de los intereses económicos británicos en un territorio colonial que estaba bajo la administración de otra potencia. Con ese propósito, se analiza la labor del primer cónsul británico en Filipinas, John Farren, durante cinco años concretos, 1853-1857, un periodo marcado por el comercio del arroz, el auge del azúcar, la apertura de nuevos puertos en las islas, el nombramiento de vicecónsules en las principales áreas de producción de materias primas para la exportación extranjera, y el propósito de luchar contra la mano de obra esclava y abrir mercados desprovistos de trabajo servil.

Palabras Clave: Filipinas, Gran Bretaña, Consulado británico en Manila, Comercio británico en Filipinas, John William P. Farren.

\section{The British Consulate in Manila, a CaSe of Institutional Support for Penetra- TION IN THE EXTRA-EUROPEAN MARKETS OF THE XIX CENTURY}

This article is focused on the study of the British consulate in Manila, as an example of institutional support for the penetration and consolidation of British economic interests in a colonial territory that was under the administration of another power. For this purpose, the work of the first British consul in the Philippines, Jobn Farren, is analyzed during five specific years, 1853-1857. This period was marked by the rice trade, the sugar development, the opening of new ports on the islands, the appointment of vice consuls in the main areas of 
production of raw materials for foreign export, and the purpose of fighting against labour slave.

KEYWORDS: Philippines, Great Britain, British Consulate in Manila, British Trade with the Philippines, John William P. Farren

\section{Introducción}

Este trabajo se inserta dentro del proyecto «Imperialismo, Mercantilismo, Liberalismo: las experiencias española y francesa de acceso a los mercados extraeuropeos», uno de cuyos ejes se centra en el análisis de cómo los gobiernos europeos intervinieron sobre poderes soberanos en distintos territorios a fin de obtener ventajas políticas y económicas y de favorecer en esos espacios tanto los intereses nacionales como los de sus comerciantes e inversores. Uno de los objetivos propuestos en ese eje era evaluar la influencia de los apoyos institucionales en la apertura de mercados ultramarinos bajo el dominio de otra potencia, en el desarrollo del libre comercio y en la obtención de una legislación favorable a sus intereses. ${ }^{1}$

En ese marco, este artículo presenta un estudio de caso sobre el uso estratégico de los cónsules con fines políticos y comerciales. Aborda, así, el análisis del consulado de Gran Bretaña en Manila como ejemplo de soporte institucional para la penetración y consolidación de los intereses económicos británicos en un territorio colonial que estaba bajo la administración de otra potencia. Al tiempo, pone de relieve la vinculación entre la creación del consulado y la preocupación del Gobierno británico por conseguir acabar con la mano de obra esclava y abrir un mercado del azúcar desprovisto de trabajo servil. Para ello, se va a analizar la labor desarrollada por el primer cónsul británico en Filipinas, John Farren, durante cinco años concretos, 1853-1857, un período marcado por el auge del azúcar en Filipinas, la apertura de nuevos puertos en las islas y el nombramiento de vicecónsules en las principales áreas de producción de materias primas para la exportación extranjera. A través de la correspondencia e informes intercambiados por el cónsul y sus superiores en la metrópoli, podremos llegar a conocer los intereses británicos en Filipinas y en su entorno y calibrar el papel del cónsul Farren en la exitosa penetración de Gran Bretaña en el mercado filipino; veremos las razones para la creación del consulado en 1844, muchos años después de Francia y de Estados Unidos, a pesar de que Gran Bretaña era el principal exportador e importador en las islas; desentrañaremos las tareas

1. Este trabajo se desarrolla en el marco de dos proyectos de investigación: IMERLIB «Imperialismo, mercantilismo, liberalismo. Las experiencias española y francesa de acceso a los mercados extraeuropeos (años 1770-años 1890)», Casa de Velázquez-UPF, 2018-2020 y «Los cónsules extranjeros en Filipinas y el mar de China, siglo XIX», PID2019-106311GB-I00, Ministerio de Ciencia e Innovación 2019, dentro del cual se desarrollará un estudio del consulado británico en Manila durante la Administración española, en el largo plazo (1844-1898). 
desarrolladas por el cónsul en Manila; la sutil y constante presión ejercida para conseguir los beneficios que los británicos deseaban; su labor para cambiar las reglas del juego gracias a la capacidad que su puesto le otorgaba para negociar con las autoridades españolas; sus relaciones con los gobernantes coloniales, con los comerciantes de su país asentados en el archipiélago filipino, y con otros cónsules y extranjeros con intereses en las islas.

El artículo centrará su atención en varios asuntos especialmente destacados: las relaciones del cónsul británico con la administración española, evaluando su capacidad de acción e influencia; el papel desempeñado por el cónsul en la apertura de nuevos puertos al exterior y en el nombramiento de vicecónsules británicos en esos puntos; las consideraciones del cónsul británico respecto a la función del cuerpo consular extranjero en Filipinas; el desarrollo de las actividades económicas en el archipiélago, y en especial de las exportaciones de arroz, del auge del azúcar y del modo de operar de las compañías británicas; y las acciones emprendidas a favor de la abolición de la mano de obra esclava.

El trabajo se inserta historiográficamente en dos líneas de investigación potentes y bien desarrolladas. Por un lado, se inscribe en el interés por varias cuestiones: el desarrollo de los imperios occidentales, especialmente en Asia y el Pacífico; ${ }^{2}$ la paulatina penetración comercial y el posterior asentamiento extranjero en ese área, y más concretamente en el Índico y en el Mar de China; ${ }^{3}$ la apertura de China y los intereses internacionales en el área; ${ }^{4}$ y la creación y desarrollo de las sociedades coloniales. ${ }^{5}$

Por otro lado, la investigación se incluye en los estudios dedicados a la función consular, un campo de trabajo que en los últimos años ha experimentado una profunda renovación. El interés por la labor de los cónsules y su papel dentro de la política exterior de un Estado, o dentro de las relaciones diplomáticas, ha sido un tema clásico de la historia

2. Bayly, Christopher A., Imperial Meridian: The British Empire and the World 1780-1830, London, Routledge, 1989. Baily, Chistopher A., The Birth of Modern World: Global Connections and Comparisons, 1870-1914, Oxford, Blackwell, 2004. Darwin, John, After Tamerlane: The Global History of Empire since 1405, New York, Allen Lane, 2007. Burbank, Jane; y Frederich Cooper, Imperios. Una nueva visión de la Historia Universal, Barcelona, Crítica, 2012. Curtin, Philip, The world and the West: the European Challenge and the Overseas Response in the Age of Empire, Cambridge, Cambridge UP, 2000. Thompson, Andrew, Empire and Globalisation: Network of People, Goods and Capital in the British World, c. 1850-1914, Cambridge, Cambridge UP, 2010. Osterhammel, Jürgen, The Transformation of the World: A Global History of the Nineteenth Century, Princeton, Princeton UP, 2014. Todd, David, Velvet Imperialism: French Informal Empire and Economic Life in the Nineteenth Century, Princeton, Princeton UP, 2021.

3. Cheong, W.E, «Changing the Rules of the Game (The India-Manila Trade: 1785-1809)», Journal of Southeast Asian Studies, n. ${ }^{\circ}$ 1/2, 1970, pp. 1-19. Van Dyke, Paul A., The Canton Trade: Life and Enterprise on the China Coast, 1700-1845, Hong Kong, Hong Kong UP. 2005. Tremml-Werner, Birgit, «The Global and the Local: Problematic Dynamics of the Triangular Trade in Early Modern Manila», Journal of World History, n. ${ }^{\circ}$ 23, 2012, pp. 555-586. Permanyer, Ander, «Opium after the Manila Galleon: The Spanish involvement in the opium economy in East Asia (1815-1830)», Investigaciones de Historia Económica, n. ${ }^{\circ}$ 10, 2014, pp. 155 164.

4. Greenberg, Michael, British Trade and the Opening of China, 1800-1842, Cambridge, Cambridge UP, 1951. Tarling, Nicholas, Imperialism in Southeast Asia, London, Routledge. 2001. Bickers, Robert, The scramble for China. Foreign Devils in the Qing Empire, London, Allen Lane, 2011.

5. Huetz de Lemps, Xavier; François Dumasy y Odile Goerg, Les sociétes coloniales à l'âge des Empires: Afrique, Antilles, Asie, Paris, Bréaf, 2012. 
de las relaciones internacionales. ${ }^{6}$ También la historia cuantitativa analizó a través de fondos consulares el comercio internacional, elaboró tablas de exportaciones e importaciones, y subrayó las motivaciones económicas detrás de determinadas políticas. ${ }^{7}$ A partir de los años noventa del siglo XX, aparecieron nuevos trabajos sobre la historia social e institucional de los cónsules, sobre su función política y económica, y sobre su utilidad y efectos en la sociedad. Desde entonces se han realizado numerosos trabajos dedicados al análisis de la función consular, cómo se formaban los cuerpos consulares y cómo funcionaban. Se han desarrollado estudios sobre aspectos más concretos, como la adquisición, tratamiento y utilización de la información por parte de los cónsules. Se ha analizado la utilidad de los cónsules en la extensión del comercio en determinados espacios y su apoyo a los comerciantes y a las compañías de su país. Se ha indagado sobre la incidencia de los cónsules en la definición de los intereses de los Estados en la escena internacional, su papel como defensores de los intereses nacionales, su influencia en procesos de globalización, o su función en la protección de los extranjeros, en la creación de un sentimiento de identidad nacional en el exterior y en los trámites de naturalización. ${ }^{8}$

Es en ese cruce de disciplinas entre imperios y cónsules, donde se asienta este trabajo, que aportará un análisis de la función del consulado británico en Filipinas, un espacio muy poco abordado por otros trabajos, dentro de esos debates historiográficos.

\section{Intereses británicos en Filipinas}

La relación de los británicos con Filipinas comenzó en fechas muy tempranas, cuando las islas todavía estaban cerradas al comercio europeo pero barcos ingleses, en tránsito desde puertos asiáticos o desde Australia, surcaban ya aquellas aguas. Se incrementó en el con-

6. Desde los trabajos tempranos de: Platt, Desmond, The Cinderella Service: British Consulssince 1825, London, Longman Books, 1971; a los más recientes de: Badel, Laurence, «Les acteurs de la diplomatieéconomique de la France au XX ${ }^{e}$ siècle: les mutations du corps des attachéscommerciaux (1919-1950)», Relationsinternationales, n. ${ }^{\circ} 114,2003$, pp. 189-211.

7. Por ejemplo, Filippini, J.P. et al., Dossiers sur le commerce français en Méditerranée orientale au XVIII siècle, Paris, 1976.

8. Ulbert, Jörg; G. Le Bouëdec (dir.), La fonction consulaire à l'époque moderne. L'affrrmation d' une institution économique et politique (1500-1800), Rennes, 2006. Jörg Ulbert, Jörg; Lukian Prijac (dir.), Consuls et services consulaires au XIX siècle. Die Welt der Konsulateim 19. Jabrbundert.Consulship in the 19th Century, Hamburg, Verlag, 2010. Aglietti, Marcella; Manuel Herrero Sánchez y F. Zamora Rodríguez (dir.), Los cónsules de extranjeros en la Edad Moderna y a principios de la Edad Contemporánea, Madrid, 2013. Jesné, Fabrice (ed.), Les consuls, agents de la présense française dans le monde, XVIII-XIX siècles, Rennes, Presses Universitaires de Rennes, 2017. Goey, Ferry de, Consuls and the Institutions of Global Capitalism, 1783-1914, London, New York, Routledge, 2016. Marzagalli, Silvia; Jörg Ulbert (dir.), «De l'intérêt d'être consul en Méditerranée, XVII ${ }^{\mathrm{e}}$ XXe siècle (dossier)», Cabiers de la Méditerranée, 98, 2019, pp. 7-177. Bartolomei, Arnaud; et al. (dir.), «La chancellerie consulaire française (XVI $\mathrm{e}-\mathrm{XX}^{\mathrm{e}}$ siècle): attributions, organisation, agents, usagers», Mélanges Revue d'bistoire Maritime, n. ${ }^{\circ}$ 13, 2016. Marzagalli, Silvia; Maria Ghazali y Christian Windler (dir.), Les consuls en Méditerranée, agents d'information (xvie-xxe siècle), Paris, Classiques Garnier, 2015. Bartolomei, Arnaud; Guillaume Calafat y Jörg Ulbert (dir.), De l'utilité commerciale des consuls. L'institution consulaire et les marchands dans le monde méditerranéen (XVII'-XIXe siècle), Rome-Madrid, Casa de Velázquez-EFR, 2018. 
texto de la Guerra de los Siete Años, durante la cual los británicos ocuparon Manila de 1762 a 1764, período en el que tuvieron la oportunidad de conocer el valor de este enclave como puerto frente a las costas asiáticas. Y se consolidó definitivamente a partir de 1834, cuando Manila se abrió oficialmente al tráfico internacional. En principio, los británicos operaban como exportadores de productos filipinos —inicialmente arroz, textiles, conchas de tortuga y productos tropicales - que vendían en puertos del entorno. Posteriormente, según fue cambiando la demanda internacional, se dedicaron a la exportación de otros cultivos que proporcionaban mayor margen de beneficio, tales como azúcar, tabaco, índigo, café o abacá, que se destinaban ya a mercados europeos, americanos o australianos.

En el caso de las Filipinas españolas, en los primeros años, la actuación de comerciantes británicos particulares y de grandes empresas que operaban por el Índico, el Pacífico y el Mar de China fue previa a cualquier intervención gubernamental. No fue necesaria esa acción institucional porque, por un lado, las casas de comercio, las navieras y las instituciones británicas tenían una alta capacidad y un hábito muy desarrollado a la hora de conquistar y operar en nuevos mercados. Por otro lado, había grandes compañías británicas, frecuentemente aliadas con socios de otros países, que ya estaban operando en el área y que tenían establecidas en otros lugares bases en las que apoyarse. Además, el gobierno británico estaba ya asentado oficialmente en ese escenario, desde India a Hong Kong, tenía soberanía sobre puertos tan importantes como Singapur y contaba con barcos en la zona. En esas condiciones, Gran Bretaña no estableció, pues - no sintió la necesidad de establecer- - un consulado específico en Filipinas hasta la década de 1840, a pesar de la paulatina penetración de sus comerciantes en el archipiélago. No obstante, antes de esa fecha y desde épocas muy tempranas, el gobierno británico respaldó los intereses de sus nacionales en Filipinas y en las islas españolas del Pacífico, y envió representantes oficiales o barcos de guerra siempre que fue necesario defender sus posiciones. Además, fue integrando los intereses particulares de sus comerciantes en los planteamientos generales de la política gubernamental en el área, hasta el punto de que ya no se trataba solo de defender los intereses de sus nacionales, sino de salvaguardar los propios objetivos del gobierno.

En esa línea, la creación de un consulado en Filipinas en la década de 1840 respondió a intereses comerciales concretos en el archipiélago, pero también a planteamientos económicos y estratégicos más generales por parte del gobierno, en los que influyeron la definición de sus propias directrices políticas, el contexto internacional y determinadas dinámicas globales, tales como la consolidación del imperio y el desarrollo del comercio británico en el área, las guerras del opio, la penetración occidental en China, la evolución mundial del mercado del azúcar, la lucha contra la mano de obra esclava, la promoción de políticas librecambistas, el control de rutas y medios de comunicación o las rivalidades coloniales entre diferentes potencias.

En ese contexto general, influyó sin duda el cambio de posición de los británicos en las islas. Si en los primeros tiempos operaban a través de agentes locales, encargados de recolectar los productos que compraban a los productores filipinos antes de la llegada de 
cada barco, al abrirse oficialmente las islas al exterior en 1834, y al aumentar el interés del tráfico comercial, los británicos se implicaron también en la producción, establecieron empresas en el archipiélago, crearon plantaciones, e importaron maquinaria que modernizó los métodos de trabajo. Por un lado, entre los años 1820 y 1850 la exportación de arroz filipino, especialmente hacia China, generó importantes beneficios a las empresas implicadas en ese negocio. Por otro lado, en los años treinta, y aún más a partir de los años cincuenta, tras la apertura de los puertos filipinos y el aumento de la demanda australiana, la exportación de azúcar filipino experimentó un notable crecimiento. Además, a pesar de la existencia de un monopolio sobre el tabaco que no se eliminó hasta 1882, a partir de 1820 se aprobó la exportación de cigarros, y a partir de 1837 también la de las hojas de tabaco, un sector en el que se adentró alguna firma británica. Finalmente, la extensión de los cultivos, la modernización de la producción gracias a la introducción de maquinaria moderna, las compras de productos destinados a la exportación y el transporte de esos productos, demandaron créditos para afrontar todas esas actividades, una actividad en la que también se involucraron importantes empresas británicas. De igual forma, se interesaron por la importación de artículos que las islas necesitaban y por introducir en Filipinas bienes británicos, así como por el transporte de efectos, personas y correos. Y, finalmente, acabaron invirtiendo en otros sectores relacionados con la creación de infraestructuras, como la construcción del único ferrocarril que existía, The Manila Railway Co., o el tendido del cable telegráfico que unía Manila con Hong Kong. En ese tiempo se instalaron en las islas técnicos e ingenieros que participaron en el proceso de modernización de las infraestructuras en las islas. El nivel de negocios llegó a ser tan importante que justificó la apertura de sucursales de bancos británicos en las islas, entre los cuales destacaron The Hong Kong E Shanghai Banking Corporation o The Chatered Bank of India, Australia and China. Al implicarse los británicos cada vez más en las actividades económicas del archipiélago, unido a los planteamientos generales del gobierno en el área, se vio la conveniencia — convertida en una creciente necesidad- de que se asentaran en las islas representantes oficiales de su gobierno que defendieran sus intereses y consiguieran mayores derechos y beneplácitos para sus actividades. Esa realidad quedó reflejada en la documentación generada por los cónsules británicos en Filipinas, que va a ser la base de este artículo. ${ }^{9}$

9. Este trabajo se basa fundamentalmente en la documentación del consulado británico en Manila, albergada en The National Archives (TNA), Kew, Reino Unido. Se pueden consultar, no obstante, algunas obras interesantes referentes a los británicos en Manila: Bowring, John, A visit to the Philippine Islands, 1859, versión on line en Hathi Trust Digital Library. Quiason, Serafin D., English «Country Trade» with the Philippines, 16441765, Quezon City, University of the Philippines Press, 1966. Cheong, W. E, «Changing the Rules of the Game (The India-Manila Trade: 1785-1809)», Journal of Southeast Asian Studies, n. ${ }^{\circ} 1 / 2,1970$, pp. 1-19. Tarling, Nicholas, «Some Aspects of British Trade in the Philippines in the Nineteenth Century», Journal of History, $\mathrm{n}^{\circ}{ }^{\circ} 9$, 1963, pp. 287-327. Legarda, Benito, After the galleons: Foreign trade, economic change E entrepreneurship in the nineteenth century Philippines, Quezon City, Ateneo de Manila UP, 1999. 


\section{Razones para la creación de un consulado británico en Manila e instrucciones al partir el primer cónsul a Filipinas}

En ese marco, en mayo de 1844 se decidió la creación de un consulado en Manila por razones geoestratégicas y económicas muy evidentes. Por un lado, muy poco tiempo antes había tenido lugar la primera guerra del opio entre Gran Bretaña y China, concluida con la firma del tratado de Nanjing en 1842. En él se ponía fin al sistema de comercio con China exclusivamente a través de Cantón, se abrían cinco puertos chinos al tráfico internacional (Cantón, Amoy, Fuzhou, Ningbo y Shanghái), en los cuales los extranjeros podrían residir libremente, y se cedía Hong Kong a Gran Bretaña. A ojos de los británicos, el asentamiento en ese puerto dotaba de nuevo interés al archipiélago filipino, vecino inmediato de este enclave. ${ }^{10}$

Por otro lado, se habían establecido ya en Manila los consulados de otros países —en especial el de Francia, en una fecha tan temprana como 1824 y de forma más efectiva desde 1836, o el de Estados Unidos, en 1817- Se consideró entonces que Gran Bretaña, que aspiraba a la hegemonía en la zona, y que era además la nación con mayores intereses en Filipinas, no debía retrasar la consolidación oficial de su presencia. ${ }^{11}$

Al tiempo, otras razones prácticas de estrategia comercial británica exigían la inmediata presencia de un representante oficial en Filipinas. La exportación de arroz estaba muy desarrollada y el azúcar, el tabaco y el abacá filipinos eran sectores en alza, en los que diferentes casas británicas tenían crecientes intereses. Junto a ello, buena parte del comercio, tanto de exportación como de importación, estaba controlado por empresas británicas. Además, en 1834, el Parlamento británico aprobó la abolición de la esclavitud y promulgó una serie de medidas que favorecían la entrada al mercado británico de azúcar producido por mano de obra libre. Ello hizo que la atención se desviara de las tradicionales áreas esclavistas de las Indias Occidentales hacia territorios azucareros que empleaban otros modos de producción. En ese contexto, en los primeros años de la década de 1840, el gobierno británico quería proponer que su mercado admitiera únicamente el azúcar que un funcionario de su país hubiera certificado que no se había producido con mano de obra esclava. Al tiempo, el Parlamento británico estaba estudiando un cambio en los aranceles que podría beneficiar al azúcar filipino. Ambas medidas reafirmaban la conveniencia de que un representante oficial del gobierno defendiera los intereses de los británicos en Filipinas sobre el terreno. ${ }^{12}$

10. Fairbank, John K., Trade and Diplomacy on the China Coast. The opening of the Treaty Ports, 1842-1854, Harvard UP, Cambridge, 1969. Lovell, Julia, The Opium War: Drugs, Dreams and the Making of China, London, Picador, 2011. Martínez-Robles, David, «Constructing sovereignty in Nineteenth century China: the negotiation of reciprocity in the Sino-Spanish Treaty of 1864», International History Review, n. ${ }^{\circ}$ 38/4, 2016, pp. 719-740.

11. Para el caso francés, ver el artículo de Xavier Huetz de Lemps en este mismo dossier. También, Mac Hale, Thomas; Mary C. Mac Hale, Early American-Philippine Trade: The Journal of Nathaniel Bowditch in Manila, 1796, New Haven, Yale University Southeast Asia Studies, 1962.

12. Este tema está trabajado en este artículo a través de la correspondencia citada entre el gobierno británico y el nuevo cónsul en Filipinas. 
De tal forma, en la primavera de 1844 se decidió la creación de un consulado en Manila. El primer titular fue John William Perry Farren, que anteriormente había sido cónsul general en Siria (Damasco) y en Jerusalén. Fue nombrado cónsul en Manila el 30 de mayo de 1844, con el apoyo del secretario de Estado de Asuntos Exteriores, Lord Aberdeen, y ocupó el puesto durante veinte años, hasta su muerte en agosto de $1864 .{ }^{13}$ Antes de partir hacia Filipinas, Aberdeen envió a Farren unas instrucciones en las que se explicaba lo que el gobierno esperaba al crear ese consulado. ${ }^{14}$ Una vez en Filipinas, le indicaba, el cónsul debía mantener unas maneras conciliadoras, buscando siempre arreglos amigables ante los problemas, en vez de seguir procesos legales formales, siempre más caros, largos y farragosos. Debía procurar el mejor entendimiento posible con todos, tanto con las autoridades coloniales como con la población de las islas, puesto que cuanto más armoniosas fueran las relaciones, más fácilmente se podrían conseguir los objetivos británicos en el archipiélago. El cometido principal del cónsul en Filipinas, decían las instrucciones, sería recoger y trasmitir cualquier información útil o interesante relacionada con el comercio, la navegación y las situaciones locales que pudieran afectar a intereses británicos. ${ }^{15}$ Se le subrayaba también que los intereses comerciales en Filipinas eran tan importantes que el Foreign Office había creído necesario destinar allí un agente de forma permanente. Finalmente, se señalaba, expresamente, que iba a haber cambios en la normativa de aduanas respecto al azúcar y esa era la razón principal por la que se le enviaba a Filipinas. Una vez allí, una de sus misiones debía ser certificar que el azúcar que se remitiera a Gran Bretaña o a sus posesiones estuviera producido por mano de obra libre. No se admitiría ninguna otra posibilidad, para luchar, así, de todas las maneras posibles, contra la esclavitud y la trata de esclavos. ${ }^{16}$

En este trabajo, he decidido centrar la atención, dentro del largo período que Farren ejerció como cónsul en Filipinas, en cinco años concretos, de 1853 a 1857, justo el período marcado por la apertura de nuevos puertos al exterior, tratando de aprehender las preocupaciones del cónsul, las cuestiones de las que se ocupó, el día a día en el desempeño del puesto, y la influencia que en su trabajo tuvieron tanto el contexto internacional, como la administración colonial, la sociedad filipina y la situación local, siempre con la mirada puesta en calibrar la efectividad del cónsul en la defensa y en la penetración de los intereses británicos en Filipinas.

13. Foreign List forming a complete British Diplomatic and Consular Handbook, London, Harrison, 1864. George Hamilton-Gordon, conde de Aberdeen, diplomático y político conservador, llegó a ser Primer Ministro de Gran Bretaña entre 1852 y 1855. Antes de ello fue secretario de Estado para Asuntos Exteriores en dos ocasiones, entre 1828 y 1830, durante el gobierno del duque de Wellington, y entre 1844 y1846, durante el mandato de Robert Peel, y en ambos períodos contó con Farren como cónsul británico.

14. The National Archives (TNA), FO 72/663, Draft n. 1, Aberdeen a Farrell, 1 de julio de 1844. «The Queen has been graciouslypleased to appoint John William Perry Farren, Esq., to be Her Majesty's Consul in the Philippine Islands». The London Gazette, 1844.

15. TNA, FO 72/663, Draft n. 1, Aberdeen a Farrell, 1 de julio de 1844.

16. TNA, FO 72/663, Draft. n.2 y Draft n. 3, Aberdeen a Farrell, 1 de julio de 1844. 


\section{Las relaciones del cónsul con la administración colonial española}

En ese tiempo he analizado con detalle la relación del cónsul con la administración española, y en especial con los capitanes generales y otros altos funcionarios, tratando de observar, sobre todo, la capacidad de acción e influencia del cónsul cerca de las autoridades coloniales.

Farren intentó mantener buenas relaciones con las autoridades españolas, no meterse en asuntos internos, evitar conflictos y actuar como elemento conciliador entre los residentes extranjeros en las islas, protegiendo los intereses de los británicos establecidos en ellas o de paso hacia otros destinos. Era consciente de cuál debía ser su cometido, y procuró desarrollar al máximo su capacidad de acción y su influencia para potenciar el comercio y el progreso en Filipinas en beneficio de su país y de sus nacionales. Para ello mantuvo numerosas reuniones con los sucesivos gobernadores, con comandantes de marina, intendentes, jueces y auditores, con alcaldes mayores y algún gobernadorcillo, con diferentes funcionarios, con comerciantes y particulares, tratando de reunir información, influir en la adopción de decisiones que pudieran beneficiar los intereses británicos, poniendo las posiciones que defendía en directa relación con el progreso de las islas y de su metrópoli, como si todo lo que le interesara defender fuera positivo también para Filipinas y para España. ${ }^{17}$

Al observar la relación entre el cónsul y la administración colonial, una de las primeras cosas que llama la atención es la estabilidad del diplomático en su puesto frente a la rápida sucesión de gobernadores. En los años que estamos estudiando, John William P. Farren llevaba ya diez años ejerciendo como cónsul en Filipinas, y todavía se quedaría otros diez. En contraste con la sensación de continuidad en los intereses y en las posiciones del cónsul, de su firme asentamiento y arraigo en las islas, en esos cinco años pasaron por la capitanía general de Filipinas cuatro gobernadores y un interino: Antonio de Urbiztondo, marqués de Solana (julio de 1850-diciembre de 1853), Manuel Pavía y Lay, marqués de Novaliches (enero de 1854-octubre de 1854), Manuel Crespo y Cebríán (noviembre de 1854-diciembre de 1856) y Fernando de Norzagaray (marzo de 1857-enero de 1860)como gobernadores, y Ramón Montero como interino en tres ocasiones mientras partía un capitán general y llegaba a las islas su sucesor. Ante tanto cambio en la jefatura del gobierno de Filipinas, Farren subrayó la influencia que tenían en las islas los frecuentes vaivenes políticos de la Península. Cada vez que cambiaba el régimen político o el partido en el poder, cambiaba el gobernador, lo cual impedía una estabilidad en las políticas desarrolladas en el archipiélago. ${ }^{18}$

Quizás por esa rápida sucesión de gobernadores que iban y venían antes de poder comprender bien la sociedad donde tenían que ejercer su mandato, o quizás por el carácter de Farren, muy seguro de sí mismo, de sus objetivos, de sus capacidades y de su fun-

17. Para conocer mejor las Filipinas del siglo XIX, Josep M. Fradera, Colonias para después de un imperio, Barcelona, Edicions Bellaterra, 2005.

18. TNA, FO 72/904, Farren a Clarendon, 6 de diciembre de 1856. 
ción como agente de S.M. británica, a través de su documentación podría deducirse que con frecuencia el cónsul se reunía con los gobernadores recién llegados, les explicaba lo que él consideraba que sería beneficioso para el desarrollo y progreso de las islas, que en muchas ocasiones coincidía con los intereses británicos, y les insistía, aconsejaba, visitaba y escribía hasta conseguir que se adoptaran determinadas medidas.

No fue benévolo en sus juicios de la administración española. Consideraba que las autoridades españolas, muchas de ellos militares, tenían poco conocimiento de la realidad filipina y del contexto que les rodeaba, escasa experiencia administrativa, y unas nociones económicas y comerciales muy reducidas. ${ }^{19}$ Les reprochaba también que con frecuencia adolecieran de capacidad de juicio, decisión y acción, lo cual, en unas islas situadas muy lejos de la metrópoli y necesitadas de una autoridad capaz de tomar decisiones propias, rápidas y acertadas, era muy grave. Advertía, igualmente, de la desafortunada tendencia a retrasar y embarrar los temas, que quedaban años archivados en la carpeta «expedientes en trámites». ${ }^{20}$

Farren era consciente del poder que tenían los gobernadores, libres para actuar como consideraran más conveniente en el archipiélago, a menudo ignorando las órdenes de Madrid. Cuando la persona al mando del gobierno general conocía bien las islas, era ilustrado y tenía carácter y buen criterio, sus decisiones podían ser acertadas y beneficiosas para el archipiélago. Sin embargo en muchas ocasiones no se daban esas condiciones. En esos casos, señalaba Farren, en un territorio situado a 15.000 millas de distancia de Europa, una posesión remota y despóticamente gobernada por militares, abogados y oficiales poco instruidos en casi todas las cuestiones de política internacional y comercial y con muchos prejuicios ante los extranjeros, era necesario cambiar las convicciones de las autoridades, hacerles descender de esos conocimientos rudimentarios, a menudo muy elementales, contrarrestar las influencias escondidas detrás sus acciones, y calmar los perjuicios nacionales por los que, dada la susceptibilidad del carácter español, miraban con desconfianza la intervención de los extranjeros en los asuntos públicos, por muy instruidos que fueran. ${ }^{21}$

En relación a su capacidad de acción e influencia, el propio Farren defendió su actuación y los méritos conseguidos en las islas, subrayando que fue el primero que levantó la bandera británica en Filipinas. ${ }^{22}$ Había sido enviado por el gobierno de S. M. para abrir las relaciones oficiales entre esas posesiones españolas y Gran Bretaña — decía- y había cumplido sus cometidos con celo, templanza y espíritu de justicia y con la debida consideración al poder local, y había formado estrechos lazos con las autoridades españolas en los más altos puestos y con diversos sectores de la sociedad de las islas. ${ }^{23}$

Más allá de las propias declaraciones del cónsul, hubo dos asuntos a través de los

19. TNA, FO 72/876, Farren a Clarendon, 20 de abril de 1855

20. TNA, FO 72/853, cónsul Farren al Earl of Clarendon, 7 de febrero de 1854.

21. TNA, FO 72/876, Farren a Crespo, 23 de diciembre de 1854.

22. TNA, FO 72/831, Farren al marqués de Solana, 14 de diciembre de 1853.

23. TNA, FO 72/876, Farren a Crespo, 23 de diciembre de 1854. 
cuales se puede observar bien la relación del diplomático británico con las autoridades españolas y su capacidad de acción e influencia. El primero de ellos fue un problema relacionado con el correo y el franqueo de las cartas extranjeras, un asunto que afectaba a la correspondencia con los gobiernos y con las compañías con las que se mantenían negocios fuera de Filipinas. Farren explicó en un informe al Foreign Office que él mismo indujo al capitán Urbiztondo a que suspendiera el decreto con el que se iba a imponer esa tarifa en Filipinas, e indicó, en otro informe, que había tenido éxito al conseguir que dos capitanes generales retiraran una medida financiera que era injusta a nivel internacional y perjudicial para los intereses comerciales británicos, atribuyéndose un papel protagonista en esos cambios de opinión y por tanto una influencia importante sobre los sucesivos capitanes generales de Filipinas. ${ }^{24}$ Como no se acababa de arreglar el tema, cuando Crespo llegó a las islas como nuevo gobernador general, Farren le escribió una carta de 38 páginas protestando por las tarifas que se querían imponer al correo, manifestando que una restricción tal sobre la correspondencia extranjera no se daba en ninguna otra colonia, y desde luego no en los mares de Oriente, o en esa «amigable confederación de posesiones vecinas», como él las llamaba. La cuestión, decía, afectaba al comercio y al progreso en las islas, lo cual era especialmente grave en un lugar donde solo existía todavía un puerto abierto al comercio exterior, y donde el cultivo y la exportación estaban tan restringidos, lo cual iba en contra de la prosperidad de las islas. ${ }^{25}$ Según el relato de Farren, la consecuencia de las acciones del cónsul fue que Crespo recapacitó y suspendió el decreto, y no solo eso, sino que muy poco después decidió que se abrieran oficialmente los puertos de Sual, Iloilo y Zamboanga al comercio extranjero. ${ }^{26}$

\section{La apertura de nuevos puertos al exterior, el nombramiento de vicecónsules y el papel del cónsul en ese proceso}

El segundo asunto a través de la cual se puede observar cómo fue la relación del cónsul con la administración colonial y su capacidad de influencia a favor de los intereses británicos fue la apertura de los puertos al exterior y el nombramiento de vicecónsules en ellos. Convencido de la importancia y repercusión que tenían sus acciones, Farren se atribuyó un papel protagonista, tanto a la hora de convencer a los sucesivos gobernadores de la conveniencia de abrir nuevos puertos en las provincias, como a la hora de destacar vicecónsules británicos en ellos, a fin de que pudieran actuar como agentes o mediadores entre los productores locales y los exportadores internacionales.

Según Farren, después de su insistencia cerca de varios capitanes generales, en abril de 1855, Manuel Crespo aceptó abrir los puertos de Sual, Iloilo y Zamboanga al comer-

24. TNA, FO 72/876, Farren a Clarendon, 20 de abril de 1855; FO a Farren, 3 de agosto de 1855; Farren a Crespo, 23 de diciembre de 1854.

25. Ibidem, Farren a Crespo, 23 de diciembre de 1854.

26. Ibidem, Decreto aprobado por Manuel Crespo, 30 de abril de 1855. 
cio exterior. Inmediatamente, el cónsul procedió a tramitar la creación de viceconsulados británicos en ellos. Lo primero que hizo fue una gestión indirecta a través del Intendente General de Ejército y Hacienda, Carlos Groizard, tal como comentaba al Foreign Office:

Consciente de cuán celosos y sensibles son los españoles respecto a las autoridades extranjeras en su propio país, y deseoso de prevenir cualquier malentendido..., consulté con el Intendente..., que es la principal influencia de esta medida sobre los puertos en el gobierno de aquí. Traté de disponer al Intendente para que contemplara esos nombramientos de forma favorable... y el resultado de mis explicaciones fue eliminar por completo sus prejuicios y conseguir su cooperación en este asunto. ${ }^{27}$

Decidió elegir él mismo al mejor candidato para el puerto de Sual, José de Bosh, un comerciante nacido en Venezuela, que se asentó en Filipinas de forma permanente hasta el momento de su muerte en 1880, y que había sido secretario de la Real Sociedad Económica de Amigos del País, por lo que tenía estrechos lazos con comerciantes y empresarios locales. ${ }^{28}$ Sin embargo, para elegir al vicecónsul en Iloilo solicitó la colaboración de las compañías británicas. El puesto que recayó en Nicholas Loney, un empleado de la compañía Ker, que había trabajado también con Jardine Matheson y tenía las simpatías y la confianza de las principales empresas que operaban en las islas. Loney se asentó en Iloilo desde 1855 hasta el momento de su muerte por malaria, en 1869, y llegó a ser conocido como el «padre de la industria azucarera», al apostar por las posibilidades que tendrían las islas centrales del archipiélago como productoras de azúcar y como exportadoras directas a los mercados internacionales. ${ }^{29} \mathrm{Ambas}$ elecciones sobre la persona que debía ser elegido vicecónsul en cada destino fueron refrendadas por el Foreign Office. ${ }^{30}$

Farren procuró luego conseguir que el capitán general de Filipinas aprobara esos nombramientos y que el gobierno español les diera su plácet. En ese proceso surgió, no obstante, a principios de 1856, un contratiempo que ilustra muy bien las relaciones entre la administración colonial y los cónsules extranjeros. Llegaron a Manila noticias de las duras críticas que el capitán general Crespo estaba recibiendo en los periódicos de Madrid. Los partidarios de Crespo promovieron un escrito a su favor que fuera firmado por los cónsules extranjeros en Filipinas. El documento fue tramitado por el cónsul de Bélgi-

27. Ibidem, Farren a Clarendon, 30 de junio de 1855.

28. Ibidem, Circular de Farren a los comerciantes británicos en Filipinas, 6 de junio de 1855. TNA, FO 72/904, Carta de Farren a Crespo, capitán general de Filipinas, 30 de enero de 1856; Carta del capitán general de Filipinas al cónsul británico en Manila, 3 de febrero de 1856.

29. TNA, FO 72/876, Un grupo de comerciantes a Farren, 22 de junio de 1855.; Martin Dyce \& Co. al cónsul, 25 de junio de 1855; Farren a los comerciantes británicos en Manila, 27 de junio de 1855. TNA, FO72/904, Los comerciantes británicos a Farren, 5 de enero de 1856; Farren a Clarendon, 5 de enero de 1856; Farren a Crespo, 5 de junio de 1856; Crespo a Farren, 6 de junio de 1856. Loney, Nicholas, A Britisher in the Philippines; or, The Letters of Nicholas Loney, Manila, National Library, 1964.

30. TNA, FO 72/876, F.O. a Farren, 12 de septiembre 1855 y 15 de octubre de 1855. TNA, FO 72/904, Clarendon a Farren, 22 de marzo de 1856. 
ca con el apoyo del cónsul francés. ${ }^{31}$ Farren no quiso firmarlo por considerar que los cónsules no debían inmiscuirse en asuntos internos del país donde estaban destinados, y menos criticar las opiniones de la prensa nacional. Al enterarse el capitán general de su postura preguntó por qué Farren se había convertido en su enemigo. ${ }^{32}$ Farren se temió que eso supusiera que no se aprobaran los puestos de vicecónsules británicos, y desplegó toda su artillería. Escribió al cónsul belga una larga de 40 páginas, que luego hizo públi$\mathrm{ca}$, en la que explicaba que las razones de su negativa a firmar ese documento se relacionaban con su concepción de cómo debía comportarse el cuerpo consular extranjero, y no con una inexistente oposición suya al gobernador; subrayaba mucho, además, su papel como cónsul decano y su conocimiento de las islas, como queriendo remarcar que la iniciativa debía de habérsele consultado antes de cursarla. ${ }^{33}$ Escribió también al capitán general, explicándole su situación respecto al malentendido producido. En su misiva reclamaba además una mayor apertura de las islas al comercio como forma de impulsar la economía de las islas, y resaltaba la importancia que podrían tener los vicecónsules en esa tarea. ${ }^{34}$ En esa ocasión, el gobernador reaccionó de forma inmediata, y aprobó, al día siguiente de recibir esas misivas, el nombramiento del vicecónsul británico en Sual y poco después el del vicecónsul británico en Iloilo. ${ }^{35}$

Al partir los titulares de esos puestos hacia sus destinos, Farren les recordó que su objetivo era mantener y hacer avanzar los intereses nacionales. Debían usar su influencia amistosa sobre las autoridades locales para desarrollar el comercio, extender las industrias británicas y promover las medidas que les interesaran en la zona. Debían de actuar también como agentes entre los productores locales y las compañías exportadoras británicas, e incluso extranjeras, generar información y facilitar las gestiones comerciales. Se evitaría así depender de intermediarios o que las empresas tuvieran que formar sus propias agencias o establecimientos en esos puntos. Serían los vicecónsules, a instancias del consulado, quienes realizarían esas tareas, lo cual les convertiría en figuras esenciales para los comerciantes. Debían, además, defender a sus nacionales ante cualquier problema con la administración local, mantener unas relaciones amistosas, y procurar que los problemas se resolvieran bajo jurisdicción británica siempre que fuera posible, para evitar la larga y discrecional justicia española. El cónsul y los vicecónsules a sus órdenes se convertían así, en protagonistas esenciales para la penetración económica británica en Filipinas. $^{36}$

31. Ibidem, Carta de los cónsules de Bélgica y Francia al capitán general, 4 de enero de 1856.

32. Ibidem, Farren a Clarendon, 7 de febrero de 1856.

33. Ibidem, Carta de Farren a Mr. Jenny, cónsul de Bélgica, 10 de enero de 1856.

34. Ibidem, Carta de Farren a Crespo, capitán general de Filipinas, 30 de enero de 1856.

35. Ibidem, Carta del capitán general de Filipinas al cónsul británico en Manila, 3 de febrero de 1856.

36. TNA, FO 72/904, Farren a Loney, 11 de junio de 1856; Farren a Nicholas Loney, Esq., 17 de julio de 1856. 


\section{Las actividades económicas}

Las actividades económicas estaban en el punto de mira más inmediato del cónsul. ${ }^{37}$ Desde el principio del período estudiado, Farren señaló que en las islas se vivía una creciente prosperidad, confirmada por las cuentas anuales de Filipinas, que presentaban un superávit de ingresos sobre gastos de alrededor de un millón de libras esterlinas, y ello después de pagar y mantener una administración civil y militar, un ejército de más de 8.000 hombres, una policía y unos guardacostas bien organizados, una flota compuesta por fragatas, cañoneros de vapor, algunos barcos de guerra pequeños y otras embarcaciones, tripulados por 1.736 hombres y un amplio personal naval, departamentos eclesiásticos, obras públicas y establecimientos consulares en Singapur y China. En esa optimista composición, el cónsul atribuía esos ingresos al incremento del tabaco, monopolizado por el gobierno para su manufactura y exportación, a un aumento de las rentas de aduanas, y a una aplicación más exigente de los tributos impuestos a los nativos y a los chinos. Señalaba también que para conseguir ese superávit se habían hecho grandes mejoras en la administración y en las finanzas públicas, se había incrementado la producción y la industria, y no se habían emprendido expediciones tan caras como las realizadas en años anteriores a Joló y Balanguingui. Gracias a ello, el Tesoro de las islas podía permitirse invertir en mejorar la Administración, y también prestar dinero para necesidades perentorias de la Península. ${ }^{38}$

En ese marco, en el primer informe económico del período, correspondiente al año 1853, Farren detallaba que Gran Bretaña se situaba a la cabeza de todas las operaciones, seguida muy de lejos por Estados Unidos —excepto en el campo del abacá, donde los estadounidenses eran los principales exportadores-. Se estimaba el valor total del comercio británico en Filipinas en unos 3.875.592 de libras. Respecto a las importaciones británicas a Manila, Farren reflejaba que en 1846 sumaban 695.154 libras, en 1853 sumaban 1.026.747 libras, y en 1856 se estimaban en 1.575 .000 libras. A su vez, las exportaciones en 1846 sumaban 340.884 libras, en 1853 1.002.670 libras, y en 18561.370 .000 libras. Había, pues, un incremento en todos los órdenes, que se esperaba que aumentaría aún mucho más cuando se empezara a notar el impacto de la apertura de los puertos y el desarrollo de nuevas actividades económicas. ${ }^{39}$

Explicaba, a su vez, que al comenzar la década de 1850 estaban asentadas en Filipi-

37. Para conocer mejor la economía de las islas en el siglo XIX: Corpuz, Onofre, An Economic History of the Philippines, Quezon City, University of the Philippines Press, 1997. Larkin, John A., Sugar and the Origins of Modern Philippine Society, Berkeley, University of California Press, 1993. Owen, Norman, «The Rice Industry of Mainland Southeast Asia: 1850-1914», Journal of the Siam Society, n. ${ }^{\circ}$ 59, 1971, pp. 75-143. Owen, Norman, Prosperity without Progress: Manila Hemp and Material Life in the Colonial Philippines, Quezon City, Ateneo de Manila UP, 1984. De Jesus, Edilberto, The Tobacco Monopoly in the Philippines: Bureaucratic Enterprise and Social Change, 1766-1880, Quezon City, Ateneo de Manila UP, 1980. Legarda, Benito, After the galleons..., cit.

38. TNA, FO 72/831, Farren al Earl of Clarendon, 5 de diciembre de 1853.

39. Ibidem, Farren al Earl of Clarendon, 31 de diciembre de 1853. 
nas unas diez empresas británicas, más otros pequeños comerciantes que operaban por cuenta propia. Entre las empresas más señaladas estaban Martin Dyce \& Co.; W. R. Paterson \& Co.; Ker \& Co.; Holliday Wise \& Co.; Butler Sykes \& Co.; Constable Wood \& Co.; J. W. Lewis; Rawson Cresswell \& Co.; Middletons Blundell \& Co.; B. A. Barretto\& Co.; y J. Rogers \& Co. Es interesante anotar que en la información relativa a estas empresas aparece que la mayor parte de ellas tenían sucursales en otros puertos del entorno como Singapur, Hong Kong, Shanghái, o Batavia; que buena parte de ellas partían de Liverpool y alguna de Glasgow; o que la última de ellas operaba en Joló. ${ }^{40}$

Las actividades económicas principales a las que Farren dedicó mayor atención fueron el arroz, el azúcar y la negociación de unas condiciones de operación lo más favorables posibles para los intereses británicos, como veremos a continuación. No obstante, hubo otras cuestiones menores como fueron el tabaco, la gutapercha o los derechos de bandera a los que también se refirió.

Respecto al tabaco, los británicos exportaron en 1856 diez millones de cigarros a Gran Bretaña, treinta millones a Australia y treinta millones a Singapur e India. ${ }^{41}$ Hubieran estado interesados en incrementar su intervención en el campo del tabaco si se hubiera procedido al desestanco. Sin embargo, Farren explicó a su gobierno que las necesidades económicas de España no permitían liberalizar un sector que podría crecer mucho más si se desestancara su cultivo y su venta, lo que le convertiría en un artículo importante para la exportación extranjera. Había sectores españoles que apoyaban la liberalización, pero las necesidades de Madrid, las muchas propiedades implicadas y los miles de personas dependientes hacían muy difícil esa transformación. Se había estudiado varias veces un cambio, pero siempre se había frenado esa iniciativa desde Madrid. De hecho, todavía debían pasar varias décadas antes de proceder al desestanco, ya en la década de $1880 .{ }^{42}$

En 1855, Farren escribió sobre la gutapercha, un árbol que crecía en Zamboanga y con cuyo látex se fabricaba goma. Señaló que era quizás la única mercancía que podía ser atractiva en ese puerto recientemente abierto al tráfico internacional. Sin embargo, el capitán general había concedido por decreto el monopolio de ese producto a un comerciante español. Se trataba de Salvador Elio y Ezpeleta, un destacado abogado y político carlista que en 1851 fue a Filipinas, ingresó en la carrera judicial y ocupó el cargo de magistrado de la Audiencia de Manila hasta 1873. El asunto le sirvió a Farren para señalar la parcialidad y discrecionalidad de los gobernadores españoles a la hora de conceder privilegios económicos a determinados círculos. ${ }^{43}$

En esos años, Farren destacó, igualmente, que el permiso diferencial de bandera beneficiaba a los barcos españoles, por lo que era frecuente que los bienes europeos llegaran a Singapur o a Hong Kong en barcos británicos o europeos, y desde allí se traspasa-

\footnotetext{
40. TNA, FO 72/761, List of British Mercantile Houses established at Manila in the year 1848.

41. TNA, FO/927, Informe económico del cónsul Farren, marzo de 1857.

42. TNA, FO 72/904, Farren a Clarendon, 18 de julio de 1856.

43. TNA, FO 72/876, Farren a Clarendon, 5 de agosto de 1855.
} 
ran a barcos españoles a bordo de los cuales llegaban a Filipinas para pagar menores derechos de aduana. ${ }^{44}$ Este sería un tema al que los cónsules británicos durante la Administración española tendrían que prestar una detenida atención. Pero antes a Farren le correspondió ocuparse del arroz y del azúcar.

\section{La exportación de arroz y el modo de operar de las compañías británicas}

Al llegar a Filipinas, Farren se encontró con que, más allá del azúcar que tanto se había señalado, la exportación de arroz tenía una importancia muy notable. Antes de que en los años treinta se adoptara una política más aperturista, el comercio del arroz estaba sujeto a las estrictas normas españolas. El comercio en las provincias estaba cerrado a los extranjeros, que tenían confinadas sus actividades en Manila. El tráfico costero no estaba permitido a los barcos de otros países y los buques locales solo podían exportar desde un número limitado de puertos provinciales. Además, el gobierno podía prohibir la exportación de arroz cuando lo considerara poco conveniente para sus intereses, tal como ocurría, por ejemplo, si la producción era escasa o si los precios no eran favorables.

La mejor manera para que empresas extranjeras operaran en el mundo del arroz era a través de agentes locales, encargados de comprar el grano a los productores isleños, y de barcos españoles, autorizados a exportar arroz desde determinados puertos. Por ello, cuando la poderosa compañía británica Jardine Matheson decidió implicarse en el mundo del arroz filipino con objeto de exportarlo a China, donde existía una gran demanda de este producto, buscó socios locales. Operó de una manera bastante habitual en la época, prestando dinero a productores y distribuidores, e incluso financiando la compra de barcos en los que transportar el producto que le interesaba. ${ }^{45}$

Así, en los años 1820 y 1830, Jardine Matheson se alió con William Kierulf \& Co, una compañía radicada en Manila, que actuó como su agente en las islas comprando a productores locales y exportando el grano a Cantón. A partir de 1834, pasó a trabajar con John Shillaber, un comerciante que ya había operado con empresas en Java y en Cantón. Shillaber optó por asociarse con Eugenio de Otadui, quien al ser español podía negociar más fácilmente la compra de arroz con los alcaldes mayores de Pangasinán o Ilocos y navegar bajo bandera española. ${ }^{46}$

44. TNA, FO/927, Informe económico del cónsul Farren, marzo de 1857.

45. Tarling, Nicholas, Some Aspects..., cit. Nicholas Tarling, a quien seguimos en los siguientes párrafos, ha analizado la economía filipina en la primera mitad del siglo XIX a través de los papeles de los Jardine Matheson Archives, sitos en la Cambridge University Library, demostrando que, a pesar de estar radicada en China, esta compañía tuvo una influencia importante en varios sectores de negocios filipinos y que es una magnífica fuente de información sobre los comerciantes británicos introducidos en Filipinas.

46. Permanyer, Ander, «Españoles en Cantón: los Diarios de Manuel de Agote, primer factor de la Real Compañía de Filipinas en China (1787-1796)», Itsas Memoria. Revista de Estudios Marítimos del País Vasco, n. ${ }^{\circ}$ 7, 2012, pp. 523-546. Permanyer, Ander, «La participación española en la economía del opio en Asia Oriental tras el fin del Galeón», Tesis doctoral, Universitat Pompeu Fabra, Barcelona, 2013. 
Sin embargo, las fluctuaciones de los precios en Filipinas y en China, los tifones que a veces impedían operar, y las disposiciones del gobierno colonial dificultaron el negocio hasta el punto de que en 1838 Jardine Matheson decidió enviar a Manila a un miembro de su firma, J. Adam Smith, para controlar directamente las operaciones. Las perturbaciones de la primera guerra del opio en los años siguientes no ayudaron a mejorar la situación, y durante varios meses de 1839 y 1840 el capital filipino fue utilizado para sustentar el comercio del opio de Jardine Matheson. En 1841, Smith informó que el comercio con el arroz filipino parecía estar perdiendo interés, quedándose relegado a un producto de provincias, exportado principalmente a través de barcos españoles, mientras las grandes compañías extranjeras empezaban a dedicarse a otros productos más prometedores, como el azúcar o el abacá. De todos modos, Jardine Matheson decidió seguir operando con Otadui unos años más, llevando arroz a China, pero cada vez con menos interés y con deudas crecientes por parte de Otadui.

Posteriormente la compañía se alió con el británico M. A. Macleod, que propuso a Jardine Matheson hacerse con el control de los negocios en Manila, entrando en contacto con la rica clase de criollos y mestizos propietarios de haciendas e impulsores de diversos negocios. De acuerdo con esa sugerencia, se aliaron con B. A. Barretto, un criollo de origen indo-portugués asentado en Filipinas, que creó una compañía para operar desde Manila con el apoyo de Jardine Matheson, comprando a distribuidores nativos y enviando arroz a China. A través suyo siguieron operando, aunque con menor intensidad, en el mercado del arroz hasta principio de la década de 1870, cuando las exportaciones de arroz de Cochinchina, Rangún y Siam afectaron al tráfico de este producto en el sudeste asiático. De hecho, el puerto de Sual, dedicado preferentemente a las exportaciones de arroz, fue perdiendo importancia hasta su clausura en los años 1880.

El cónsul Farren estuvo atento a los intereses y problemas de las empresas británicas que operaban en el mundo del arroz, y nombró en cuanto le fue posible a un vicecónsul británico en Sual, el principal puerto para la exportación de este grano, para que actuara como intermediario con los productores locales, sustituyendo así el papel que anteriormente habían desempeñado comerciantes chinos y otros agentes autóctonos, a fin de negociar así unas condiciones más ventajosas y más ajustadas a lo que los exportadores británicos deseaban. ${ }^{47}$

En el lustro 1853-1857, Farren subrayó en relación al arroz que, debido a la escasez de arroz y a su alto precio en China —más de 28.000 toneladas habían sido expedidas desde Filipinas-, la demanda seguía creciendo y los precios se estaban duplicando, por lo que el capitán general Crespo había aprobado un decreto prohibiendo exportar arroz desde Manila, y luego desde las provincias, a fin de evitar que el mercado interno quedara desabastecido. La exportación estaba, pues muy limitada y solo podía hacerse con licencia y a través de determinadas compañías que ejercían de corresponsales de otras empresas. Por ello les interesaba tanto destinar a vicecónsul británico a las provincias 
arroceras, a fin de que pudiera actuar como mediador de los intereses nacionales en ese sector. $^{48}$

Pocos meses después, siempre en función de la oferta, la demanda y los precios del mercado, Farren informó de que Crespo había eliminado las restricciones a la venta de arroz, una medida que consideró beneficiaba mucho a la agricultura, al transporte de bienes y a los intereses comerciales, así como a los capitalistas del país, españoles y extranjeros, llevando a Filipinas capitales por un valor cercano al medio millón de dólares. ${ }^{49}$

\section{El auge del azúcar}

A partir de los años 1830, el azúcar se convirtió en el principal producto de exportación de Filipinas. Al principio su destino fundamental era Gran Bretaña, aunque posteriormente el mercado se amplió hacia Australia, China, Bombay y, a partir de los años sesenta, también a Europa.

A fin de incrementar las exportaciones británicas de azúcar, Farren trabajó para que se abrieran más puertos filipinos al comercio exterior. Para ello, se entrevistó con sectores isleños interesados en fomentar el comercio, y en especial con los miembros de la Real Sociedad Económica de Amigos del País, y también con los diversos gobernadores españoles que se sucedieron en el cargo antes de conseguirse la apertura de Iloilo, Sual y Zamboanga.$^{50}$ Esta política aperturista interesaba a aquellos británicos que querían implicarse en el cultivo y manufacturación de los productos a exportar, o que deseaban introducirse en los mercados provinciales, una vez que éstos fueran abiertos al tráfico internacional. Sin embargo, no gustó a las empresas británicas asentadas en Manila, que controlaban desde allí las redes de producción y exportación y pensaron que se verían perjudicadas por la apertura de las provincias y la multiplicación de los cauces para llegar a los productos y para distribuirlos a los mercados exteriores. El cónsul Farren tuvo que ocuparse de lidiar los intereses enfrentados de estas dos tendencias, apoyando siempre una mayor apertura de las islas y el desarrollo de las exportaciones directas desde distintos puertos, aunque el tema le costara algún desencuentro con comerciantes de su país. ${ }^{51}$

Farren respaldó también el nombramiento de Nicholas Loney como vicecónsul en Iloilo, decidido a convertir varias de las islas Visayas en la base fundamental de este pro-

48. TNA, FO 72/876, Informe de Farren a Clarendon, 15 de mayo de 1855.

49. TNA, FO 72/927, Farren a Clarendon, 31 de diciembre de 1857.

50. TNA, FO 72/761, Farren a Palmerston, 2 de marzo de 1849; FO 72/772, Farren a Palmerston, 30 de octubre de 1850; FO 72/795, Farren a Palmerston, 16 de abril, 21 de abril y 28 de junio de 1851; FO 72/831, Farren a Russell, 29 de marzo de 1853, y Farren a Clarendon, 5 de diciembre de 1853; FO 72/876, Farren a Clarendon, 2 de junio de 1855 y 30 de junio de 1855; FO 72/904, Farren a Clarendon, 7 de febrero de 1856 y 6 de diciembre de 1856.

51. TNA, FO 72/876, Ker and Co. y R. Jardine a Farren, 23 de junio de 855; Farren a los comerciantes británicos en Manila, 25 de junio de 1855; Farren a Clarendon, 4 de julio de 1855; FO 72/904, Farren a Clarendon, 5 de enero de 1856 y Farren a Crespo, 31 de enero de 1856. 
ducto. Sin embargo, la apertura del puerto de Iloilo no significó un inmediato despegue de las exportaciones de azúcar, ni tampoco el brusco aumento de los ingresos por aduanas que esperaban los españoles. Fue un proceso lento que tardó años en dar frutos, pero que cuando lo hizo produjo grandes beneficios (ver Cuadro 1). En 1844 fueron exportadas 10.000 toneladas de azúcar. En 1856 esa cantidad había ascendido a 50.000 toneladas. En 1892, el año de mayor tonelaje de la etapa española, se llegó hasta las 165.407 toneladas de azúcar exportado desde Iloilo. ${ }^{52}$

CuAdRO 1. Exportaciones de azúcar, 1836-1920.

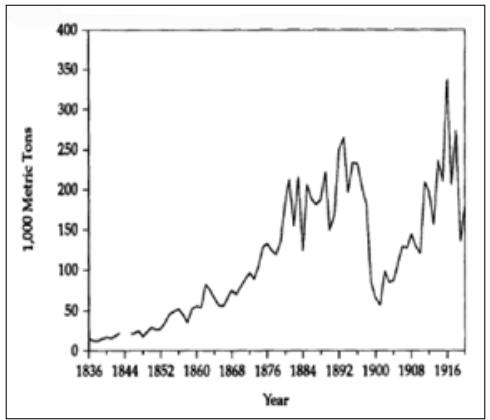

FUENTE: John Larkin, Sugar and the Origins of Modern Philippine Society..., cit., p. 47.

Con objeto de aumentar las posibilidades de cultivo, la introducción de maquinaria y el incremento de las exportaciones y de las importaciones, Loney llegó incluso a viajar a Gran Bretaña y a España para conseguir más inversores, mayores facilidades para el comercio internacional y una política aduanera más liberal, así como para convencer a industriales y navieros la capacidad de compra de las provincias filipinas. Sin embargo, en los primeros años, poner el mecanismo en marcha no fue un proceso fácil, y la correspondencia de Farren y de Loney está llena de referencias a las resistencias de las casas británicas a operar más allá de los cauces establecidos, o a asentarse en las islas para cultivar la tierra y transformar el producto. Por lo general, preferían dedicarse al comercio bruto, o a la financiación de operaciones. Tuvieron que esforzarse también para que la llegada de productos británicos a Filipinas no se hiciera solo a través de Manila, sino que se aventuraran a llevar la carga a otros puertos de provincia. ${ }^{53}$

El azúcar no solo atrajo a compañías británicas asentadas en Filipinas, sino también a grandes empresas operando en el Sudeste asiático, que funcionaban en las islas a través de agentes locales y se beneficiaron de la actuación del vicecónsul Loney. Nos encontramos, así, de nuevo, a Jardine Matheson actuando en este campo, aunque de manera más limitada

52. Foreman, John, The Philippine Islands, New York, Charles Scribner's Sons, 1899, pp. 295-296. Aguilar, Filomeno Jr., «Beyond Inevitability: The Opening of the Philippine Provincial Ports in 1855», Journal of Southeast Asian Studies, n. ${ }^{\circ} 25,1994$, pp. 70-90.

53. TNA, FO 72/927, Loney a Farren, 12 de abril de 1857; FO 72/1017, Loney a Farren, 10 de 1861. 
que en el mundo del arroz. Operó frecuentemente con la compañía estadounidense Russell \& Sturgis, apoyó puntualmente a varias firmas de Bombay interesadas en comprar azúcar filipino a bajo precio para llevarlo a India, y financió la compra y envío de azúcar a distintos destinos - Inglaterra, San Francisco, Sídney, Hong Kong, Shanghái...- a través de distintos consignatarios como Otadui, Macleod o Barretto. A veces, en estas operaciones con azúcar la empresa, en creada en 1834 con el nombre de Magniac, Smith \& Co., aparecía con otras denominaciones que adoptó posteriormente, como Magniac, Jardine \& Co., de Lombard Street, Londres, o como Matheson \& Co., Londres. ${ }^{54}$ En 1865 Barretto presentó a Nicholas Loney a Jardine Matheson para que les informara del azúcar producido y exportado desde Visayas, explicándoles que era el mayor empresario de Iloilo y el fundador de la industria del azúcar en Negros, gracias sobre todo a su distribución de maquinaria a crédito. A partir de entonces, Jardine Matheson tramitó sus peticiones de azúcar a través de Loney \& Co., en Iloilo, y Loney, Ker and Co. en Cebú, ordenando a su oficina en Manila que enviaran dinero a estas firmas para que pudieran hacer el acopio de azúcar. ${ }^{55}$

En los años 1853-1857, Farren señaló, en relación con el azúcar, que era el principal artículo de exportación enviado fundamentalmente a Gran Bretaña y Australia. El azúcar enviado a Gran Bretaña en 1856 ascendía a 24.759 toneladas. El azúcar enviado a Sídney en ese mismo año sumaba 14.307 toneladas. El precio había subido un $20 \%$ respecto al año anterior, $1855 . .^{56}$

En su correspondencia, Farren dejó también testimonio de numerosos barcos británicos que transportaron azúcar de Filipinas a Australia, aunque cuando se refirió a ellos no fue para resaltar la importancia de ese comercio, sino para dar cuenta de la pérdida de distintos barcos en diferentes huracanes o incidentes marítimos, un tema del cual también debería ocuparse como parte de sus funciones como cónsul. ${ }^{57}$

\section{La lucha a favor de la abolición de mano de obra esclava}

Otro problema importante tratado por el cónsul británico en Filipinas fue el referido al tráfico de trabajadores culíes. Era un tema de gran relevancia para los británicos, debido a su estrecha relación con la lucha contra la esclavitud, y ocupó un volumen importante de la documentación consular. Durante el lustro 1853-1857, Farren dedicó bastante aten-

54. Grace, Richard, Opium and Empire: The Lives and Carrieres of William Jardine and James Matheson, Montreal, McGill-Queen's UP, 2014, pp. 164, 289, 304.

55. Tarling, Nicholas, Some aspects..., cit., p. 19. Respecto a otros productos, Jardine Matheson no estuvo demasiado interesado por el comercio de abacá, que quedó en manos estadounidenses. Compró, sin embargo, cigarros manufacturados por el monopolio gubernamental para venderlos en las posesiones británicas en Asia. Finalmente, estuvo también interesado en la importación a Filipinas de textiles británicos, a pesar de que las principales compañías que se dedicaron a ese negocio fueron Wise and Co. y Ker McMicking, a las que probablemente en algún momento Jardine Matheson pudo financiar, según puede entreverse a través de la documentación de Macleod.

56. TNA, FO/927, Informe económico del cónsul Farren, marzo de 1857.

57. TNA, FO 72/831, Farren al Earl of Clarendon, 1 de agosto de 1853. 
ción a esa cuestión, y en sus despachos se reflejó la evolución del tema. En los primeros años, el cónsul se vio sobrepasado por los acontecimientos, sin unas directrices claras que seguir, respondiendo ante hechos suscitados en Filipinas por barcos británicos que llevaban trabajadores chinos hacia otros destinos, pero que por accidente tuvieron que recalar en las islas. En los últimos años del período, se evidenció que se había establecido ya una colaboración entre el cónsul británico en Manila y el gobernador de Hong Kong para este tema, se había fijado el procedimiento que se debía seguir en la emigración de culíes desde China, y se habían dispuesto unos certificados que debía otorgar el gobernador de Hong Kong y que debían exigirse si llegaban a Manila barcos británicos con trabajadores chinos. La experiencia había mostrado también los serios conflictos que podrían surgir en esas emigraciones, las muertes, enfermedades y pérdidas indeseadas, los farragosos procesos judiciales, los devastadores efectos de las malas prácticas, e incluso el coste que los malos procedimientos podía acarrear al Tesoro nacional o a los particulares y a las compañías de seguros que tenían que encargarse de los barcos, las tripulaciones, las deudas contraídas, etc. Por ello, el cónsul vigiló que los barcos británicos que acudieran a Filipinas respetaran la legalidad y no cometieran irregularidades.

La llegada de trabajadores chinos a Filipinas era una realidad asentada desde hacía muchos años, hasta el punto de haberse convertido en un sector de población muy relevante en las islas. Por lo general, los pasajeros chinos llegaban a Manila en buques de diversas naciones. Ese transporte de trabajadores era un negocio lícito, directamente relacionado con el cometido de tantas empresas navieras. No obstante, dada la preocupación por el tráfico esclavista, se cuestionó la posibilidad de que en esos viajes se produjera un tráfico ilegal de personas o se transportaran trabajadores forzados, una situación especialmente perseguida por los británicos. Además, las autoridades británicas alertaron sobre la posible utilización de Filipinas como punto de escala en el tráfico irregular de culíes y en el tráfico de mano de obra esclava hacia otros destinos. ${ }^{58}$

En un principio, Farren señaló que las personas transportadas a Filipinas desde China no eran culíes forzados, sino pasajeros que viajaban libremente, con frecuencia por motivos de trabajo, pero que pagaban su pasaje sin coacciones, y que, por muy duras que fueran sus condiciones laborales, una vez cumplidos sus compromisos de trabajo, o pagadas las deudas contraídas para pagarse el pasaje, podían moverse libremente y cambiar

58. Arensmeyer, Elliott, «The Chinese Coolie Labor Trade and the Philippines: An Inquiry», Philippine Studies, n. ${ }^{\circ}$ 28/2, 1980, pp. 187-198. Este autor elaboró una tesis doctoral en 1971 sobre el cónsul John William Farren, leída en el Ateneo de Manila University, que lamentablemente no me ha sido posible consultar. También, Sugaya, Nariko, «Chinese Immigrant Society in the Latter Half of the 18th-century Philippines: Strategy for Survival in Response to Spain's New Chinese Policy», Ang See, Teresita (ed.), Intercultural Relations, Cultural Transformation, and Identity. The Ethnic Chinese: Selected Papers Presented at the 1998 ISSCO Conference, Manila, Kaisa para Sa Kaunlaran, Inc., 2000, pp. 553-570. Murakami, Ei, «The End of the Coolie Trade in Southern China: Focus on the Treaty Port of Amoy», en Suzuki, Hideaki (ed.), Abolitions as a Global Experience, National University of Singapore, Singapur, 2015. Mònica Ginés, «A Philippine "coolie trade": Trade and exploitation of Chinese labour in Spanish colonial Philippines, 1850-98», Journal of Southeast Asian Studies, n. ${ }^{\circ}$ 51/3, 2020, pp 457-483 y «Exploiting Chinese Labour Emigration in Treaty Ports: The Role of Spanish Consulates in the "Coolie Trade" International Review of Social History, n. ${ }^{\circ}$ 66/1, 2021, pp. 1-24. 
sus actividades. Debido a la normativa existente, explicó Farren, lo más beneficioso para ese negocio era transportar pasajeros chinos hacia Filipinas en barcos españoles, que pagaban menos derechos y aduanas. Normalmente los trabajadores chinos pagaban su pasaje y su comida, y los capitanes de los barcos les proveían de agua. Muy raramente, decía Farren, iban a Filipinas como culíes, sino que en su mayoría figuraban como mecánicos o pequeños comerciantes que iban por cuenta propia. ${ }^{59}$

Un asunto más complejo era la posibilidad de que Filipinas, y en especial las islas del sur del archipiélago, se utilizaran como punto de escala en el tráfico de culíes forzados hacia otros destinos. De hecho, desde los primeros años de su estancia en Filipinas, el cónsul británico en Manila denunció casos de barcos que pasaron por las islas llevando esclavos, e incluso informó sobre la intervención de algún barco de guerra británico para liberar a esos pasajeros. ${ }^{60}$ Señaló también Zamboanga, Joló, otros puntos de Mindanao y las costas de Borneo como lugares de recalada para buques que transportaban población forzada, normalmente destinada hacia destinos más allá de Filipinas.

Entre los casos que tuvo que afrontar Farren en esos años, uno de los más tempranos, y quizás el más complicado a nivel legal, fuera el del British Sovereignity, un barco británico que el 18 de agosto de 1852 dejó Amoy rumbo a La Habana llevando 313 culíes a bordo y que tras diversas vicisitudes acabó recalando en Manila. Al ser un barco británico, Farren se vio obligado a intervenir y procurar resolver los muchos problemas que presentaba, dando puntual cuenta a su gobierno de todo lo tratado. ${ }^{61}$ No eran cuestiones solo humanitarias o directrices gubernamentales para acabar con la trata. En el tráfico de culíes se dirimían también cuestiones económicas que suponían importantes gastos para los comerciantes, las navieras, las compañías de seguros británicas y, en última instancia, para la Administración que debía asumir los costes de esas operaciones. El segundo caso del que tuvo que ocuparse Farren en estos años fue el del Waverley, un barco de Estados Unidos que en 1855 partió de Amoy rumbo a Perú, llevando 450 culíes chinos a bordo. Debido a la muerte y enfermedad de parte de la tripulación, el buque se vio obligado a acudir a Manila. Estando allí, y para evitar que los trabajadores chinos escaparan, se cerraron las compuertas del barco y 251 de ellos murieron por asfixia. Tales circunstancias originaron una causa judicial dirimida en los tribunales de Justicia españoles - la situación más temida por los británicos—. Farren de nuevo tuvo que intervenir al haber varios británicos entre la tripulación. ${ }^{62}$ En 1855 se planteó otro caso que, aunque no se produjo

59. TNA, FO 72/904, Farren a Sir John Bowring, 28 junio 1856; Farren a Clarendon, 28 de junio de 1856.

60. Por ejemplo, en 1844 Farrenin formaba de un barco británico en viaje entre Hong Kong y Java que se vio sorprendido por una tormenta, por lo que tuvo que recalar en el sur de Filipinas, donde fue atacado por piratas que se apoderaron de varios esclavos que iban a ser vendidos en el puerto de destino. TNA, FO 72/663, Farren a Foreign Office, 4 de diciembre de 1844.

61. FO 72/831, Farren al Earl of Malmesbury, 7 de marzo de 1853; Farren al Earl of Malmesbury, 9 de marzo de 1853; Farren a Lord Russell, 16 de abril 1853; Farren al Earl of Clarendon, 20 de mayo 1853; Farren al Earl of Clarendon, 10 de agosto de 1853; Farren al Earl of Clarendon, 28 de septiembre de 1853.

62. TNA, FO 72/876, Farren a Clarendon, 6 de noviembre de 1855. TNA, FO72/904, Farren a Clarendon, 5 de febrero de 1856; Farren a Clarendon, 4 de noviembre de 1856. 
en aguas filipinas, pudo tener repercusión en el archipiélago. En ese año, se detuvo en el puerto de Amoy a un barco con bandera británica, el Inglewood, que transportaba 43 niñas chinas menores de ocho años para que trabajaran cono cigarreras, sin que la investigación pudiera determinar si las niñas iban a ser conducidas a Manila, a Macao o a Cuba. El asunto volvió a alertar a las autoridades británicas sobre la posibilidad de la utilización de Filipinas en el tráfico ilegal de culíes. ${ }^{63}$

Ante el aumento del tráfico, Farren consultó con el gobernador de Hong Kong, Sir John Bowring, superior jerárquico suyo en el área, cómo debía actuar cuando barcos británicos trasladaran trabajadores chinos a Filipinas. Bowring subrayó la firma de la Chinese Passenger Act, en 1855, que sería reforzada posteriormente por una enmienda de 1858 contra los comerciantes británicos que se implicaran en el tráfico de mano de obra ilegal. A la luz de esos acuerdos, Farren debía impedir que ningún británico se implicara en Filipinas en el tráfico ilegal de culíes, comprobando que todos los trabajadores estuvieran debidamente certificados y legalizados. En el caso de que los trabajadores chinos llegaran a Filipinas a bordo de barcos británicos, debían exigirles que el pasaje estuviera certificado por la Chinese Passengers Act. Según la cláusula 3. . de ese documento, el gobernador de Hong Kong tenía el poder de declarar cuál debía ser la duración de un viaje. Al tiempo, en la cláusula 4. ${ }^{a}$ se decía que para un viaje de más de siete días de duración se debía expedir un certificado de emigración. El problema estribaba en que el viaje de Hong Kong a Manila tenía una duración variable. Podía hacerse en cinco días, o podía exigir quince, dependiendo del tiempo y los monzones. Un trayecto medio a Manila desde Amoy, donde embarcaban la mayoría de los culíes, solía ser de siete días, justo en el límite de lo señalado por la normativa. Era, pues, discutible si los trabajadores chinos que llegaran a Manila desde China debían de llevar certificado de emigración o no. Sin embargo, los problemas prácticos planteados en la época provocaron que se recomendara que todos los barcos llegaran con sus correspondientes certificados. ${ }^{64}$

\section{Conclusiones}

El consulado británico en Manila, como caso de estudio, presenta un interés singular por la originalidad del contexto: el cónsul desarrollaba su labor en una colonia, y no en un territorio soberano. Por ello la mayor parte de sus relaciones las mantuvo con los administradores coloniales, en vez de con las autoridades en la metrópoli. Filipinas era, además, en las primeras décadas del siglo XIX, un territorio que adolecía de una importante debilidad imperial y en el que los extranjeros podrían penetrar económicamente sin encontrar grandes resistencias. Había, pues, un cierto juego para la actuación de otras potencias.

63. TNA, FO 228/184, Minutes of the Court of Inquiry, Amoy, 23 de marzo de 1855, cit., por Arensmeyer, Elliot, The Chinese Coolie..., cit., p. 192.

64. TNA, FO72/904, Farren a Bowring, 28 junio de 1856; Bowring a Farren, 28 de julio de 1856; Farren a Clarendon, 18 de agosto de 1856; Farren a Clarendon, 9 de diciembre de 1856. 
Aún así, hay que tener claro que Gran Bretaña no pretendió desarrollar ningún tipo de imperialismo informal en Filipinas, ni apoderarse de territorios donde estuvieran asentados los españoles, ni ejercer su administración sobre el archipiélago. Solo quiso obtener beneficios económicos en un lugar con atractivas posibilidades de explotación, donde sería posible apoyar y fomentar las exportaciones e importaciones que ya estaban realizando particulares y compañías de su país, así como abrir nuevas posibilidades de mercado, de inversión y de actuación en un área de creciente interés estratégico. El archipiélago estaba convenientemente situado frente a las costas chinas, y en especial frente al nuevo establecimiento británico en Hong Kong, cerca del puerto de Singapur, y en ruta hacia Australia, el Pacífico y América. Sus opciones de negocio eran, además, complementarias a los de otros lugares del área donde los británicos tenían sus intereses centrados en textiles, té, opio y otros productos.

No hay que olvidar, no obstante, que el gobierno británico era consciente de que en un momento dado podría ser interesante adquirir en el archipiélago una base estratégica frente a una mayor expansión en Asia Oriental, la adquisición de otros puertos en el norte de China o alguna eventualidad internacional que hiciera recomendable esa posibilidad. Tampoco podemos obviar que Gran Bretaña tuvo un especial interés por el área del sur de Filipinas - Joló, Zamboanga, Mindanao, Borneo-y que negoció con los sultanes que gobernaban esos territorios la firma de tratados que permitieran la expansión económica y estratégica de los británicos, con los consecuentes problemas con el gobierno español. Sin embargo, estas cuestiones estaban más allá de la labor del cónsul Farren y exceden los propósitos de este artículo.

En ese esquema, hemos visto, el gobierno británico decidió crear un consulado en 1844 por motivos económicos, políticos y estratégicos. En esa fecha, las empresas de su país estaban ya introducidas en el comercio con las islas. Hacía tiempo que los comerciantes británicos operaban por sí mismos en el área y se mostraban fuertes, seguros e independientes en sus actuaciones. Estaban acostumbrados a introducirse y conquistar otros mercados. Tenían apoyos en el área, podían operar en importantes puertos y contaban con una poderosa red de comunicaciones y servicios bajo dominio británico, colaboraban con grandes compañías británicas e internacionales que se movían con soltura por esas aguas, y confiaban en lograr respaldo financiero para sus operaciones aunque el territorio en el que operaban no estuviera administrado por su país. Quizás por ello, el nombramiento del cónsul fue tan tardío en comparación con otras naciones. Al final, la creación del consulado respondió a varias razones: defender las posiciones de los británicos ya introducidos en el mercado filipino en un momento en que la coyuntura en las islas se complicaba por la presencia de cada día más intereses cruzados; negociar con las autoridades españolas las ventajas pretendidas desde una posición oficial; solucionar los problemas del mercado internacional del azúcar y asegurar nuevas áreas que pudieran certificar que no se estaba produciendo con mano de obra esclava; refrendar la voluntad británica de moralizar el comercio internacional, estableciendo así una clara relación entre el despliegue consular británico y el abolicionismo; y respaldar la expansión británica en el área, y en especial del cercano establecimiento en Hong Kong. 
¿Hasta qué punto podríamos decir, entonces, que el nombramiento del cónsul reforzó la penetración británica en Filipinas? Su presencia y su actuación permitió llevar a cabo una serie de acciones importantes: negociar directamente con las autoridades coloniales desde la posición de fuerza que le otorgaba el saber que estaba actuando en nombre de su gobierno; abrir nuevos cauces que facilitaron el diálogo entre las partes; realizar gestiones que cambiaron las reglas del juego y coadyuvaron a transformar la legislación; procurar un marco favorable para los intereses británicos; proporcionar información relevante respecto a las islas o las medidas adoptadas o a adoptar por el gobierno español; defender a sus nacionales en los conflictos que se suscitaron; y establecer vicecónsules en puntos estratégicos que actuaron como puente entre la sociedad y los productores del lugar y los residentes y compañías británicas operando en el área.

El caso del cónsul John William P. Farren fue, además, especialmente interesante por su larga permanencia de veinte años en Filipinas, en los cuales vio pasar a nueve gobernadores generales y a varios interinos. Destacó, pues, su conocimiento de las islas frente a la volatilidad de los gobernadores. Fue una persona de carácter, que no siempre tuvo las mejores relaciones con el Foreign Office, ni con los comerciantes británicos en Filipinas, aunque se entendió muy bien con algunos de ellos, caso, por ejemplo, de Nicholas Loney, con los círculos de negocios más aperturistas, y también con algunos gobernadores generales y algunos miembros de la administración colonial, gracias a lo cual éstos aceptaron muchas de las sugerencias de Farren para promover el comercio en las islas y para proteger los intereses británicos en ellas.

Realizó numerosos informes del estado económico de las islas y de las oportunidades de negocio, llegando a afirmar en un ataque de optimismo que «no hay en el mundo una posición colonial que tenga más intereses de prosperidad y riqueza comercial que Filipinas». Apostó claramente por el libre comercio y la apertura de las islas. Negoció constante e insistentemente con las autoridades coloniales la consecución de las medidas pretendidas por su gobierno y por los comerciantes de su país. Solucionó problemas y ejerció de puente e informante. Informó sobre la legislación española y la aprobación de normativas que podían afectar a su país o a sus conciudadanos y trató de influir para que se cambiase el marco legal cuando fue desfavorable para sus intereses. Protegió los derechos de los británicos en las islas y de los ciudadanos de su país que pasaron por el archipiélago o que se vieron envueltos en conflictos en aquel área.

Farren fue una persona muy celosa de su puesto y de la posición que ocupaba en las islas. Subrayó mucho que él fue el primero en izar la bandera británica en Filipinas, así como los logros que había conseguido para promover los intereses británicos en el archipiélago. Se atribuyó un papel protagonista en la apertura de los puertos filipinos y en la creación de viceconsulados británicos en las provincias, lo cual propició que agentes británicos ejercieran como mediadores entre los productores locales y los exportadores extranjeros, en especial compañías británicas. Hizo valer también su papel como cónsul decano en Filipinas, y como representante del país con mayores intereses y volumen de comercio en las islas, tratando de marcar las directrices del cuerpo consular y de ejercer un papel preponderante entre los cónsules extranjeros en las islas. 
Sus comentarios sobre la administración española y sobre la situación del archipiélago fueron interesantes y bastante realistas. Reflejó la inestabilidad y la fragilidad del régimen colonial, a pesar de los esfuerzos reformistas realizados, de los que resaltó que se enfrentaron a enormes obstáculos que paralizaron muchas de las iniciativas planteadas. Fue consciente también del impacto que tenía en Filipinas la inestabilidad política de la Península, la parálisis que eso producía en la administración, la poca separación de poderes entre las distintas instancias de gobierno, y la existencia de abusos y corrupción. Era un tema que le preocupaba, convencido como estaba de que la prosperidad estaba ligada a un buen gobierno de las islas. Conocía la arbitrariedad de las decisiones de las autoridades, pero también sabía que su misión era conseguir que adoptaran medidas que pudieran ser favorables a los comerciantes de su país, por lo que con frecuencia se aprovechó de aquella circunstancia y ejerció de interlocutor en situaciones concretas a fin de conseguir la concesión de una oportunidad de negocio especialmente favorable, una mayor movilidad por el territorio, o el asentamiento de alguna compañía o comerciante en algún lugar determinado.Cumplió, por tanto, con su papel de agente de la penetración económica británica en Filipinas, favoreciendo la expansión comercial de su país y promoviendo los intereses de Gran Bretaña en el área.

\section{Archivos consultados}

The National Archives (TNA), Kew, Reino Unido

\section{Fuentes impresas}

Bowring, John, A visit to the Philippine Islands, 1859, versión on line en Hathi Trust Digital Library. Una visita a las islas Filipinas, Manila, Imp. de Ramírez y Giraudiez, 1876.

Consular Reports, No.1932, Report on Trade and Commerce of the Philippine Islands for the year 1896.

Foreign List forming a complete British Diplomatic and Consular Handbook, London, Harrison, 1864.

Foreman, John, The Philippine Islands, New York, Charles Scribner's Sons, 1899.

Loney, Nicholas, A Britisher in the Philippines; or, The Letters of Nicholas Loney, Manila, National Library, 1964.

The London Gazette, 1844.

\section{Bibliografía}

Aglietti, Marcella; Manuel Herrero Sánchez y F. Zamora Rodríguez, F. (dir.), Los cónsules de extranjeros en la Edad Moderna y a principios de la Edad Contemporánea, Madrid, 2013.

Aguilar, Filomeno Jr., «Beyond Inevitability: The Opening of the Philippine Provincial Ports in 1855», Journal of Southeast Asian Studies, n. ${ }^{\circ} 25,1994$, pp. 70-90. 
Arensmeyer, Elliott, «The Chinese Coolie Labor Trade and the Philippines: An Inquiry», Philippine Studies, n. ${ }^{\circ}$ 28/2, 1980, pp. 187-198.

Badel, Laurence, «Les acteurs de la diplomatieéconomique de la France au XXe siècle: les mutations du corps des attachés commerciaux (1919-1950)», Relations internationales, n. ${ }^{\circ} 114,2003$, pp. 189-211.

Bartolomei, Arnaud; et al. (dir.), La chancellerie consulaire française (XVI ${ }^{e}-X X^{e}$ siècle): attributions, organisation, agents, usagers, Mélanges Revue d'bistoire Maritime, n. ${ }^{\circ}$ 13, 2016.

Bartolomei, Arnaud; Guillaume Calafat y Jörg Ulbert (dir.), De l'utilité commerciale des consuls. L'institution consulaire et les marchands dans le monde méditerranéen (XVII ${ }^{e}$ XIX ${ }^{e}$ siècle), RomaMadrid, Casa de Velázquez-EFR, 2018.

Bickers, Robert, The scramble for China.Foreign Devils in the Qing Empire, London, Allen Lane, 2011.

Burbank, Jane; Frederich Cooper, Imperios. Una nueva visión de la Historia Universal, Barcelona, Crítica, 2012.

Bayly, Christopher A., Imperial Meridian: The British Empire and the World 1780-1830, London, Routledge, 1989.

-, The Birth of Modern World: Global Connections and Comparisons, 1870-1914, Oxford, Blackwell, 2004.

Cheong, W.E., «Changing the Rules of the Game (The India-Manila Trade: 1785-1809)», Journal of Southeast Asian Studies, n. ${ }^{\circ}$ 1/2, 1970, pp. 1-19.

Coates, P. D., The China Consuls: British Consular Officers, 1843-1943, Hong Kong, Oxford UP, 1988.

Corpuz, Onofre, An Economic History of the Philippines, Quezon City, University of the Philippines Press, 1997.

Philip Curtin, The world and the West: the European Challenge and the Overseas Response in the Age of Empire, Cambridge, Cambridge UP, 2000.

Darwin, John, After Tamerlane: The Global History of Empire since 1405, New York, Allen Lane, 2007.

De Jesus, Edilberto, The Tobacco Monopoly in the Philippines: Bureaucratic Enterprise and Social Change, 1766-1880, Quezon City, Ateneo de Manila UP, 1980.

Fairbank, John King, Trade and Diplomacy on the China Coast.The opening ofthe Treaty Ports, 1842-1854, Cambridge, Harvard UP, 1969.

Fradera, Josep M., Colonias para después de un imperio, Barcelona, Edicions Bellaterra, 2005.

Ginés, Mònica, «A Philippine "coolie trade": Trade and exploitation of Chinese labour in Spanish colonial Philippines, 1850-98», Journal of Southeast Asian Studies, n. ${ }^{\circ}$ 51/3, 2020, pp. 457-483.

—, «Exploiting Chinese Labour Emigration in Treaty Ports: The Role of Spanish Consulates in the "Coolie Trade" ", International Review of Social History, n. ${ }^{\circ}$ 66/1, 2021, pp. 1-24.

Goey, Ferry de, Consuls and the Institutions of Global Capitalism, 1783-1914, London, New York, Routledge, 2016.

Grace, Richard, Opium and Empire: The Lives and Carrieres of William Jardine and James Matheson, Montreal, McGill-Queen's UP, 2014.

Greenberg, Michael, British Trade and the Opening of China, 1800-1842, Cambridge, Cambridge UP, 1951.

Huetz de Lemps, Xavier; François Dumasy y Odile Goerg, Les sociétes coloniales à l'âge des Empires: Afrique, Antilles, Asie, Paris, Bréaf, 2012. 
Jesné, Fabrice (ed.), Les consuls, agents de la présense française dans le monde, XVIII'-XIXe siècles, Rennes, Presses Universitaires de Rennes, 2017.

Jones, Raymond A., The British Diplomatic Service, 1815-1914, Waterloo, Ont., Canada, Wilfrid Laurier UP, 1983.

Larkin, John, Sugar and the Origins of Modern Philippine Society, Berkeley, University of California Press, 1993.

Legarda, Benito Jr., After the galleons: Foreign trade, economic change E entrepreneurship in the nineteenth century Philippines, Quezon City, Ateneo de Manila UP, 1999.

Lovell, Julia, The Opium War: Drugs, Dreams and the Making of China, London, Picador, 2011.

Mac Hale, Thomas R.; and Mary C. Mac Hale, Early American-Philippine Trade: The Journal of Nathaniel Bowditch in Manila, 1796, New Haven, Yale University Southeast Asia Studies, 1962.

Martínez-Robles, David, La participación española en el proceso de penetración occidental en China, Tesis doctoral, Universitat Pompeu Fabra, Barcelona, 2007.

-, «Constructing sovereignty in Nineteenth century China: the negotiation of reciprocity in the Sino-Spanish Treaty of 1864», International History Review, n. ${ }^{\circ}$ 38/4, 2016, pp. 719-740.

—, «Los "desheredados" de la empresa imperial: la implantación diplomática de España como potencia colonial periférica en China», Historia Contemporánea, n. ${ }^{\circ}$ 57, 2018, pp. 453-489.

Marzagalli, Silvia; Maria Ghazali y Christian Windler (dir.), Les consuls en Méditerranée, agents d'information (XVI'-XX' siècle), Paris, Classiques Garnier, 2015.

Marzagalli, Silvia; y Jörg Ulbert (dir.), «De l'intérêtd' êtreconsul en Méditerranée, XVII $-\mathrm{XX}^{\mathrm{e}}$ siècle (dossier)», Cahiers de la Méditerranée, n. ${ }^{\circ}$ 98, 2019, pp. 7-177.

Murakami, Ei, «The End of the Coolie Trade in Southern China: Focus on the Treaty Port of Amoy», en Hideaki Suzuki (ed.), Abolitions as a Global Experience, Singapore, National University 2015.

Osterhammel, Jürgen, The Transformation of the World: A Global History of the Nineteenth Century, Princeton, Princeton UP, 2014.

Owen, Norman, «The Rice Industry of Mainland Southeast Asia: 1850-1914», Journal of the Siam Society, n. ${ }^{\circ}$ 59, 1971, pp. 75-143.

—, Prosperity without Progress: Manila Hemp and Material Life in the Colonial Philippines, Quezon City, Ateneo de Manila UP, 1984.

Permanyer, Ander, «Españoles en Cantón: los Diarios de Manuel de Agote, primer factor de la Real Compañía de Filipinas en China (1787-1796)», Itsas Memoria. Revista de Estudios Marítimos del País Vasco, n. ${ }^{\circ}$ 7, 2012, pp. 523-546.

-, «La participación española en la economía del opio en Asia Oriental tras el fin del Galeón», Tesis doctoral, Barcelona, Universitat Pompeu Fabra, 2013.

—, «Opium after the Manila Galleon: The Spanish involvement in the opium economy in East Asia (1815-1830)», Investigaciones de HistoriaEconómica, n. ${ }^{\circ}$ 10, 2014, pp. 155-164.

Platt, Desmond C.M., The Cinderella Service: British Consuls since 1825, London, Longman, 1971.

—, Latin America and British Trade, 1806-1914: The Merchant Adventurers, London, Harper \& Row, 1973.

Sugaya, Nariko, «Chinese Immigrant Society in the Latter Half of the 18th-century Philippines: Strategy for Survival in Response to Spain's New Chinese Policy», en Teresita Ang See (ed.), Intercultural Relations, Cultural Transformation, and Identity. The Ethnic Chinese: Selected Papers Presented at the 1998 ISSCO Conference, Manila, Kaisa para Sa Kaunlaran, Inc., 2000, pp. 553-570. 
Tarling, Nicholas, «Some Aspects of British Trade in the Philippines in the Nineteenth Century», Journal of History, n. ${ }^{\circ}$ 9, 1963, pp. 287-327.

-, Imperialism in Southeast Asia, London, Routledge, 2001.

Thompson, Andrew, Empire and Globalisation: Network of People, Goods and Capital in the British World, c. 1850-1914, Cambridge, Cambridge UP, 2010.

Todd, David, Velvet Imperialism: French Informal Empire and Economic Life in the Nineteenth Century, Princeton, Princeton UP, 2021.

Tremml-Werner, Birgit, «The Global and the Local: Problematic Dynamics of the Triangular Trade in Early Modern Manila», Journal of World History, n. ${ }^{\circ} 23,2012$, pp. 555-586.

Ulbert, Jörg; G. Le Bouëdec (dir.), La function consulaire à l'époque moderne. L'affirmation d'une institution économique et politique (1500-1800), Rennes, Presses universitaires de Rennes, 2006.

Ulbert, Jörg; Lukian Prijac (dir.), Consuls et services consulaires au XIXe siècle. Die Welt der Konsulateim 19. Jahrbundert. Consulship in the 19th Century, Hamburg, Verlag, 2010.

Van Dyke, Paul A., The Canton Trade: Life and Enterprise on the China Coast, 1700-1845, Hong Kong, Hong Kong UP, 2005.

-, Merchants of Canton and Macao: Politics and Strategies in Eighteenth-Century Chinese Trade, Hong Kong, Hong Kong UP, 2011. 